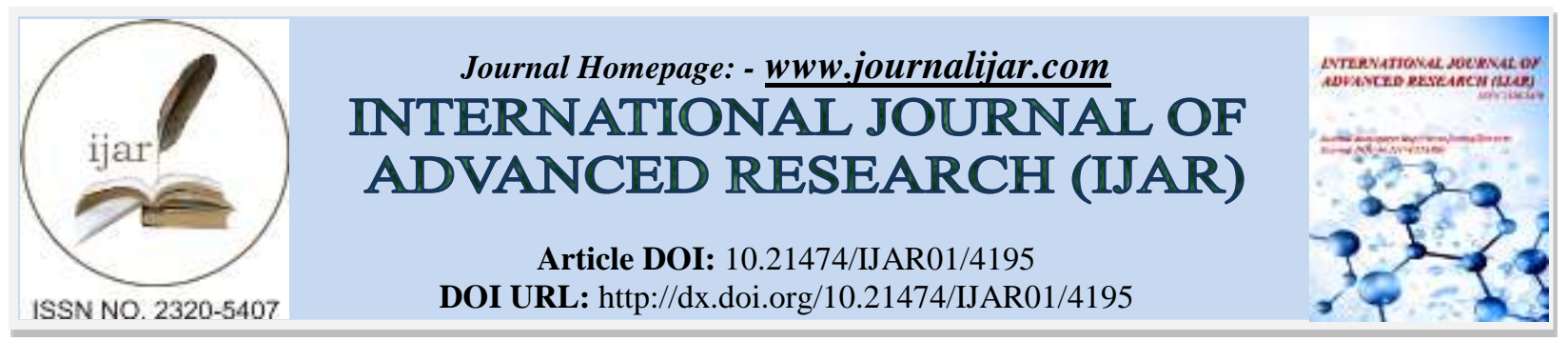

RESEARCH ARTICLE

\title{
PERFORMANCE OF BACHELOR OF SCIENCE IN INFORMATION TECHNOLOGY (BSIT) STUDENTS IN THEIR ON-THE-JOB TRAINING (OJT) FOR THE ACADEMIC YEAR 2016-2017.
}

\author{
Sherwin Banaag Sapin and Jefferson Llobit Lerios \\ Assistant Professors, College of Computer Studies, Laguna State Polytechnic University-Los Baños Campus, Los \\ Baños, Laguna, Philippines
}

\section{Manuscript Info}

Manuscript History

Received: 10 March 2017

Final Accepted: 04 April 2017

Published: May 2017

\begin{abstract}
$(\mathrm{OJT})$ is one of the success stories that may provide significant contribution to the total effectiveness of the curriculum designed and participated by stakeholders from various industry representation. Students were deployed in different companies to gain knowledge, skills, attitudes, and actual working experience for them to become more competitive upon completion of training and serve as input for their future career in their chosen field. This study aimed to assess and evaluate the OJT performance of BSIT students in their respective companies for Academic Year 2016-2017. Descriptive-survey research was employed in this study. A total of 58 students were selected to represent as the main respondents of the study. Findings revealed that their OJT performance was at "Very Satisfactory" level. The study recommended that the College of Computer Studies may establish a strong partnership and linkages with various companies, especially those with IT departments which accept student-trainees.
\end{abstract}

Copy Right, IJAR, 2017,. All rights reserved.

Students' performance in their Copy Right, IJAR, 2017, All rights reserved.

\section{Introduction:-}

On-the-job training, also known as OJT, is teaching the skills, knowledge, and competencies that are needed for employees to perform a specific job within the workplace and work environment. Employees learn in an environment in which they will need to practice the knowledge and skills taught in the on-the-job training (Heathfield, 2016).

Exposure to actual working environment plays an important role in the development of future professionals in various fields of specialization. Thru this, higher education institutions (HEIs) are establishing their best to provide an effective OJT program integrated and implemented in some of their curricular offerings.

Any organization that wants to succeed, and to continue to succeed, has to maintain workforce consisting of people who are willing to learn and develop continuously. Training and developing human capital is tremendously important in the effective management and maintenance of a skilled workforce. Training is one of the ways of improving an organization's effectiveness. In order to implement right training methods, an organization should be aware of the training methods and their effectiveness (Alipour, 2009).

Corresponding Authors: Sherwin Banaag Sapin and Jefferson Llobit Lerios 
The College of Computer Studies (CCS) of Laguna State Polytechnic University-Los Baños Campus (LSPU-LBC) offers Bachelor of Science in Information Technology (BSIT) degree program that incorporates OJT in the curriculum. Students are deployed in different companies to render their Practicum or OJT which lasts for four hundred ninety (490) hours.

This study was conceptualized to assess and evaluate the performance of BSIT students who had undergone OJT in their respective companies. Furthermore, the study will provide significant information that may serve as good input to the continuous improvement and effective delivery of the CCS' OJT Program and to other curricular programs of the University-Campus as well.

\section{Research Objectives, Questions and Hypotheses:-}

The main objective of this study is to assess and evaluate the performance of BSIT students in their OJT for the Academic Year 2016-2017 and the following questions were answered:

1. What the respondents' socio-demographic profile in terms of Age, Gender, Company Name, and Department?

2. What the respondents' mean assessment on the OJT Program of CCS in terms of College, Company, Personal and Overall?

3. What the respondents' performance evaluation score in terms of Job Knowledge, Dependability, Communication Skills, Conduct, Initiative and Creativity, Cooperatives and Relationship and Attendance and Punctuality?

4. What the respondents' level of performance in OJT?

5. What the respondents' overall perception on the level of effectiveness of OJT Program of CCS?

6. Is there any significant relationship between the respondents' socio-demographic profile and mean assessment of the OJT Program of CCS in terms of College, Company, Personal, and Overall?

7. Is there any significant relationship between the respondent's socio-demographic profile and performance evaluation score in terms of Job Knowledge, Dependability, Communication Skills, Conduct, Initiative and Creativity, Cooperatives and Relationship and Attendance and Punctuality?

8. Is there any significant relationship between the respondent's socio-demographic profile and level of performance in OJT?

9. Is there any significant relationship between the respondent's mean assessment of the OJT Program of CCS and performance evaluation score in terms of Job Knowledge, Dependability, Communication Skills, Conduct, Initiative and Creativity, Cooperatives and Relationship and Attendance and Punctuality?

10. Do the following singly or in combination predict the respondent's over-all perception on the level of effectiveness of OJT Program of CCS:
a. Socio-demographic Profile,
b. Program Assessment,
c. Performance Evaluation?

Based on the above questions, the following hypotheses were derived and tested at $5 \%$ level of significance:

1. There is no significant relationship between the respondent's socio-demographic profile and mean assessment of the OJT Program of CCS in terms of College, Company, Personal, and Overall.

2. There is no significant relationship between the respondents' socio-demographic profile and performance evaluation score in terms of Job Knowledge, Dependability, Communication Skills, Conduct, Initiative and Creativity, Cooperatives and Relationship and Attendance and Punctuality.

3. There is no significant relationship between the respondent's socio-demographic profile and level of performance in OJT.

4. There is no significant relationship between the respondent's mean assessment of the OJT Program of CCS and performance evaluation score in terms of Job Knowledge, Dependability, Communication Skills, Conduct, Initiative and Creativity, Cooperatives and Relationship and Attendance and Punctuality?

5. None among the following singly or in combination predict the respondents' over-all perception on the level of effectiveness of OJT Program of CCS:
a. Socio-demographic Profile,
b. Program Assessment,
c. Performance Evaluation. 


\section{Research Methodology:-}

The research design implemented in this study was Descriptive-Survey. This design was adopted by the researchers for they strongly believed that this was the most suited and appropriate in analyzing and interpreting the data collected and eventually to come up with better findings, conclusions, and recommendations.

The respondents of this study are the conveniently selected fourth year BSIT students that had successfully completed their OJT and attended the College' General Assembly Meeting. Moreover, this utilized the Performance Evaluation Sheet and Program Assessment Questionnaire as its main instruments to solicit the data needed for analysis and interpretations.

Furthermore, the researchers had used various statistical tests of the measurement and validation of the research questions and hypotheses.

\section{Results and Findings:-}

From the total population of 119 officially enrolled students in OJT for Academic Year 2016-2017 fifty-eight (58) were conveniently selected as target respondents. For the socio-demographic profile of the respondents in terms of Age, it was found out that the highest frequency was 20 years old and that represents twenty-three (23/58 or $39.66 \%$ ) of the total respondents which comprises of twelve (12) males and eleven (11) females.

The study identified a total of 19 companies and among these, nine respondents (9/58 or 15.52\%) completed their OJT in the Ecosystems Research Development Bureau (ERDB) of the Department of Environment and Natural Resources (DENR) located in Los Baños, Laguna, Philippines.

Based from the Department/Section/Unit of assignments, majority or thirty-nine (39/58 or 67.24\%) of the respondents completed their OJT in a Non-IT workplace (or department) and the remaining nineteen (19 or 32.76\%) were assigned in an IT-related workplace.

The performance mean scores of the respondents were based on the evaluation done by their respective immediate supervisors. With the maximum score of 15 , the highest mean score went to Cooperatives and Relationship with 14.68, followed by Conduct with the mean score of 14.59. Moreover, with the maximum score of 10, Attendance and Punctuality obtained the score of 9.24 .

The respondents' level of performance described that $46.55 \%(27 / 58)$ of the respondents obtained "Very Satisfactory" performance, followed by "Excellent" performance at 37.93\% (22/58), 12.07\% (7/58) at "Satisfactory" performance, and 2 or $3.45 \%$ "Passed." Although both the mean performances of the students in terms of Department were at "Very Satisfactory" level, those who completed their OJT in a Non-IT (mean=94.49) showed a slight higher mean over Non-IT with the mean of 92.56. Moreover, the computed mean score on the overall performance of the respondents was 93.86. This implies that the respondents were "Very Satisfactory" on their OJT performance in their assigned company workplace.

The OJT Program of CCS was assessed by the respondents. The highest computed mean of 4.46 was interpreted as "Extremely Satisfied," followed by Company with the mean of 4.33 interpreted as "Extremely Satisfied," and College with the mean of 4.19 interpreted as "Very Satisfied." The computed overall mean was 4.49 interpreted as "Very Satisfied." This dictates that the respondents were "Very Satisfied" on the implementation delivery of the OJT Program of the College of Computer Studies.

The respondents were asked about their overall assessment on the Effectiveness of OJT Program of CCS. Based on the summary of their responses, the highest frequency of 28 (48.28\%) went to "Very Effective," followed by "Slightly Effective" with 16 (27.59\%) counts, and 14 (24.14\%) responses for "Effective." The computed overall mean for the effectiveness was 4.21 interpreted as "Effective." This implies that the respondents assessed the OJT Program of CCS to be "Effective."

The correlation between the respondents socio-demographic profile and OJT Program Assessment revealed that the respondents' assessment based on Company $(\mathrm{r}=.334, \mathrm{p}=.010)$ and Personal $(\mathrm{r}=.349, \mathrm{p}=.009)$ both showed significant positive relationship with Department. This may command that students' OJT assignment/placement in any or particular department constitute to the assessment of the College' OJT Program. In addition, the overall ( $\mathrm{r}=.328$, 
$\mathrm{p}=.012$ ) assessment of the respondent had a positive significant relationship with Department and this solidified that the knowledge, skills, attitudes, and experiences gained by the students in their respective assigned departments attributed to better overall assessment of the College' OJT Program.

The correlation between the respondent's socio-demographic profile and OJT Performance Score shown that the Company displayed a negative significant relationship with the Performance Score in terms of Dependability ( $r=-$ $.323, \mathrm{p}=.013$ ) this entails that the students' performance in their chosen company may lead to better performance in terms of Dependability. Further, the correlation shown a negative relationship due to the fact that majority of the companies identified in this study were Non-IT and students themselves were responsible in finding/seeking for their place of internships.

The correlation between the respondents' socio-demographic profile and Level of Performance showed that none among the respondents' profile had any significant relationship with the overall OJT performance. This implied that the socio-demographic profile had no significant relationship with the overall performance of students in their OJT.

The correlation between the OJT Program Assessment and Performance Score revealed that the company ( $\mathrm{r}=-.621$, $\mathrm{p}=.047$ ) shown a negative significant relationship with the performance in terms of dependability. This revealed that the students' performance in terms of Dependability contributed to the better assessment of the College's OJT Program in terms of Company.

The regression analysis revealed that $11.8 \%$ of Level of Effectiveness of the College's OJT Program were explained by the Personal Assessment $\left(\mathrm{R}^{2}=.118\right)$. Further, the .839 coefficient for Personal Assessment means that for every unit increase in Personal Assessment, a .839 unit increase in Level of Effectiveness is predicted. In addition, the study revealed that Personal Assessment singly predicts the Level of Effectiveness of OJT Program of the College of Computer Studies.

\section{Conclusions:-}

1. Majority of the respondents were 20 year old males who completed their On-the-Job Trainings in Non-IT Department of their chosen Company.

2. The overall performance of BSIT Students in their OJT was at "Very Satisfactory" level.

3. The BSIT Students assigned in the Non-IT Department showed a slight higher mean performance over those entrusted in the IT-Related Departments.

4. The students were "Very Satisfied" on their assessment of the College' OJT Program.

5. The students perceived the College's OJT Program to be at "Effective" level.

6. There were significant relationship between socio-demographic profile in terms of Department and OJT Program Assessment in terms of Company, Personal, and Over-all Assessment. Hence, the hypothesis was partially upheld.

7. There were significant relationship between socio-demographic profile in terms of Company Name and Performance Score in terms of Dependability. Hence, the hypothesis was slightly upheld.

8. There were significant relationship between the respondents' profile and the mean assessment of the OJT Program of CCS.

9. There was significant relationship between the OJT mean assessment in terms of Company and Performance Score in terms of Dependability. Hence, the hypothesis was slightly upheld.

10. The OJT Assessment in terms of Personal singly predicted the Level of Effectiveness of the OJT Program of the College of Computer Studies. Hence the hypothesis was partially upheld.

\section{Recommendations:-}

1. All students who successfully completed their On-the-Job Training for the last three (3) Academic Years may be included.

2. The students had shown "Very Satisfactory" performance level in their OJT, however, effective monitoring (e.g. Regular Visits) should be employed by the assigned OJT Instructor/Professor to retain and/or elevate the OJT Performance of Students.

3. Since majority of the identified Company-Departments were those of Non-ITs, student-trainees be assigned and/or deployed in the Company's IT-Related Department as much as possible. 
4. The College (CCS) may consider appointment and/or designation of the College's OJT Coordinator whose major function is to supervise the efficient and effective delivery of OJT Program.

5. The students perceived the College's OJT Program to be "Effective." Hence, the College may consider the Development of Policies and Guidelines vis-à-vis On-the-Job Training that may serve as the student-trainees' term of reference.

6. Since the study revealed that the Student's profile, Department exhibited significant relationship on the Assessment of OJT Program, the College may consider establishment of Memorandum of Agreement (MOA) or Memorandum of Understanding (MOU) with the identified Companies that may serve as students' choices for their future OJT.

7. For the last two (2) years, the implementation of Service Management Program (SMP) in the BSIT Curriculum created a venue of opportunity for students to experience a good working environment for their OJT. However, the study recommends that establishment of strong partnerships and linkages with other IT-Industries outside SMP may be taking into considerations.

8. The conduct of Company Benchmarking within the nearby cities/municipalities that accommodates studenttrainees may be considered for recommendations to students during their Pre-Course (OJT) Orientations.

9. Since the students themselves selected their respective Companies, they tend to be more dependable on their work assignments and other activities during the span of their OJT. Though they were dependable, the study recommends that the College thru its OJT Coordinator and/or Instructor/Professor In-Charge should be responsible in providing company recommendations and suggestions to their students.

10. The students' assessment of OJT Program in terms of Company and Performance in OJT in terms of Dependability revealed a significant relationship; the study recommends that student-trainee be deployed to their preferred company provided that it is recommended by the College. Hence, it attributes to effectiveness of the College' OJT Program.

11. The College should create a diversified OJT Assessment Instrument to regularly monitor the effectiveness of its On-the-Job Training Program.

12. The College should conduct students' OJT Assessment immediately after they completed their training.

13. Consideration of the conduct of the same study to better determine and analyze the progress, performance, and effectiveness of the College's OJT Program.

\section{References:-}

1. Alipour, M., Salehi, M., \&Shahnavaz, A. (2009). A Study of on the Job Training Effectiveness: Empirical Evidence of Iran. International Journal of Business and Management, 4(11). doi:10.5539/ijbm.v4n11p63

2. Bernardo, A. C. (2015). Students' On-the-Job-Training Performance of AB Paralegal Studies. Multilingual Academic Journal of Education and Social Sciences, 2(2). doi:10.6007/majess/v2-i2/1388

3. Heathfield, S. M. (2016). Is On-the-Job Training Really Effective? Retrieved May 15, 2017, from https://www.thebalance.com/how-on-the-job-training-brings-you-value-1917941

4. Micheal, R. K. (n.d.). Job Training Effectiveness. Retrieved May 15, 2017, from https://www.scribd.com/document/214569677/Job-Training-Effectiveness 